\title{
Informação on-line: jornalista ou produtor de conteúdos?
}

Zélia Leal Adghimi

\section{RESUMO}

O trabalho apresenta um panorama geral sobre as transformaçōes que vêm ocorrendo na midia impressa brasileira, provocadas pela Internet. A produção e a distribuição da noticia em rede alteram as rotinas de trabalho dos profissionais submetidos às pressōes do "tempo real" e da "ideologia da transparência". As organizaçōes profissionais (patrōes e empregados) devem fazer face à uma nova realidade que "desconfigura" - mercado atual, desafia a legislação vigente e desestrutura conceitos tradicionais de jornalismo. Jornalista ou produtor de conteúdos? Noticia ou informaçāo? Mediador de sentidos ou veículo de transaçōes comerciais? Neste texto procuramos refletir sobre algumas questōes urgentes que envolvem o jornalista e o jornalismo na sociedade da informação.

\section{ABSTRACT}

This work gives an orentew of the changes that are hempening in the brabilian press as a result of the internet. The production and distribution of network new's has transformed the working routines of journalists subject to the pressures of "real time" and the "ideology" of tramsparency". Professional organisations (employers and employees) must face al to a new reality that is "deconfiguring" the current market, challenging existing legislation and destructuring traditional concepts of journalism. Joumalist or producer of content? News or information?' Mediator of feelings. or vehicle for commercial transactions? This study attempts to reflect on some urgent questions that imole the joumalist and joumalism in the information society.

Zélia Leal Adghirni é jornalista, professora na Faculdade de Comunicaçāo (Universidade de Brasilia) com doutorado em Comunicação pela Universidade Stendhal de Grenoble (França) e pós doutorado pela Universidade de Rennes I (apoio CAPES e ONTCIObservatório de Novas Tecnologias da Comunicação e da Informaçāo do Instituto Universitário de Tecnologia de Lannion -, Universidade de Rennes 1-França). 
Ao estudar as mudanças estruturais no jornalismo provocadas pela produção e distribuição da notícia em rede, nossa atenção será fixada particularmente no jornalismo online de Brasília. Além de capital da República, Brasília também é a « capital do jornalismo » no país tanto pelo número de jornalistas quanto pelo volume de informações diárias produzidas. Segundo o Sindicato de Jornalistas do DF, mais da metade das informações que circulam na mídia nacional tem sua origem na capital da República.

Beneficiando-se de um contigente de 6.700 profissionais com registro no Ministério do Trabalho, Brasília reúne o maior número per capita de jornalistas do país. Se considerarmos que a população do DF ( Plano Piloto, Lagos e Entorno) é de dois milhões de habitantes podemos concluir que há um jornalista para 298 habitantes. "Um assessor de imprensa para cada prédio », brinca o vice-presidente da Federação Internacional de Jornalistas ( FIJ), Francisco Sant'Anna.

Em um mercado profissional protegido e formalmente regulamentado por leis ( Ministério do Trabalho que fornece o registro profissional, Sindicato de Jornalistas que controla o exercício legal da profissão e Faculdade de Comunicação, que concede o diploma reconhecido pelo Ministério da Educação), de que maneira os jornalistas exercem a profissão diante do impacto das novas tecnologias da informação e da comunicação?

138 Os jornalistas da mídia tradicional (mídia impressa e audiovisual) evoluem dentro de um espaço profissional fortemente regulamentado. Entretanto, quando praticam o webjornalismo, são eles mesmos que transgridem estas normas. Centenas de jornalistas online trabalham sem parâmetros legais rompendo diariamente com o código convencional do jornalismo tradicional. Textos, imagens, sons, programas e bancos de dados podem ser lidos, copiados, recopiados e enviados livremente no ciberespaço. Todos estes novos suportes modificam a maneira de tratar a informação.

A Internet não elimina apenas as noções de espaço/tempo. Ela confunde as fronteiras entre jornalistas profissionais (diplomados pelas faculdades e reconhecidos pelos sindicatos) e «produtores de contéudos », segundo a definição das empresas.

Mas o que fazer dos não-jornalistas que trabalham com informações em centenas de sites e portais independentes que operam com notícias, entretenimento e comércio ?

O Sindicato de Jornalistas do DF recebe regularmente denúncias contra os « invasores da profissão ». Que fazer? Por enquanto nada, responde o presidente do Sindicato, Edgar Tavares já que não existe regulamentação definida para o exercício do jornalismo na Internet. Mas 
as mutações são vistas com apreensão nos meios sindicais que temem uma «desordem» nas estruturas profissionais. Ainda que a fatia de jornalistas online tenha alumentado de $1,91 \%$ para $2,69 \%$ entre $1994 \mathrm{e}$ $1997^{\prime}$ o Sindicato não tem como averiguar quantos não-jornalistas estão empregados nos pequenos sites e portais efêmeros que proliferam na Web.

Além das questões ligadas à "desconfiguração" do mercado provocadas pelas novas tecnologias, iremos analisar as transformações ocorridas nas rotinas produtivas das redações dos veículos de comunicalção e nos aspectos ćticos do « métier». Obscrva-se uma certa confusão cntre informação (notícias) e informação-serviço (sites-guias) e sobretudo. uma grande confusão entre o papel clássico do jornalista (função social, quarto poder, síndrome de Clark Kent) e o jornalista « copiar-colar» da Web.

Vamos propor alguns itens específicos que tratam da desregulamentação para esta debate:

1- Desregulamentação temporal (introdução do conceito de Tempo Real - TR)

2- Transformação dos papéis (jornalistas $X$ fornecedores de conteúdo)

3- Nova configuração de fronteiras entre as funções do jornalista tradicional e o jornalista institucional (imprensa $X$ assessoria institucional)

4- Desregulamentação das rotinas produtivas (precarização do trabatho)

5- Desregulamentação do status profissional (Sindicatos, Universidades)

\section{1 - A desregulamentação temporal das mídias (das "turbinas da informação" à Internet)}

Para compreender como e por que as empresas jornalísticas se adaptaram tão rapidamente ao ritmo da Internet e do Tempo Real (TR) é preciso voltar vinte anos atrás. Foi nos anos 80 que os jornais adotaram o o termo informação no lugar de notícia.

Segundo Elizabeth Brandão o declínio do conceito de notícia e sua substituição por informação não é apenas uma troca casual ou uma questão de moda e não se restringe ao jomalismo econômico ainda que aí tenha se originado. O termo está sendo usado de modo geral nos sistemas de informação online e em tempo real e traduz uma concepção 
e um modo de fazer jornalismo totalmente vinculado ao mercado e às necessidades do cliente, do "usuário da informação", conforme está sendo chamado aquele que era leitor da notícia.

A adoção das tecnologias de informação e comunicação, com um sentido operacional voltada para o mercado, bem como a visão comercial do jornal como usina de informação, causaram uma transformação no jornalismo brasileiro de grandes proporções

A influência da Universidade de Navarra (Espanha) foi decisiva para as transformações ca imprensa brasileira. A partir do final da década de 80 , professores dessa Universidade foram chamados para prestar consultoria a alguns dos principais jornais do país, introduzindo a noção de jornal como "usina deformação". Segundo esta concepção, os jornais seriam "informadutos", espécie de canais de informação que irrigam o tecido social assim como os gasodutos e oleodutos abastecem a cidade de energia. Referindo-se a estes processsos, as empresas passaram a adotar a expressão "turbinas de informação" para significar a produção do jornalismo como mercadoria de fábrica.

Desta forma, a empresa jornalística tinha que se transformar em usina de informação, disseminando uma gama diversificada de produtos destinado a diversos públicos e diversos objetivos. Aproveitavam com isso a credibilidade que já tinham granjeado junto ao público como fornecedores confiáveis de notícias além do know-how que possuíam em

140 buscar, tratar e disseminar a informação ${ }^{3}$.

A principal mudança observada nos jornais que já tinham se firmado como pólos da indústria cultural, é a diversificação de seus produtos. Os jornais se transformam em empresas jornalísticas e passam a oferecer serviços especializados, tipo agência de notícia que alimentam não apenas o próprio jornal como também clientes externos. É o início do boom das agências de notícias direcionadas para o mercado financeiro, inspiradas no modelo da agência britânica de notícias, Reuters, cuja tônica dominante é a velocidade. Começa a surgir uma nova técnica jornalística que é necessária para produzir a informação em tempo real $^{4}$ e a informação online, ${ }^{5}$ uma notícia muito curta, cujo valor está na atualidade que, por sua vez é medida em segundos.

A agência Estado foi a primeira a se lançar no tempo real. Em 1991 ela criou a agência Broadcast e conta hoje com cerca de dez mil clientes credenciados.

A adequação das empresas de jornalismo no Brasil ao noticiário online criou um espaço privilegiado na esfera pública para a discussãe dos interesses políticos e financeiros.

A "febre" do tempo real na imprensa brasileira tem suas origens na instabilidade econômica do país quando era preciso saber rapidamente 
tudo que se passaval na área financeira para evitar ou, ao menos limitar, as perdas tanto para o setor privado como para as contas do governo. A equipa econômica do governo muitas vezes serviu-se das agências de notícia para testar a receptividade dos agentes econômi$\cos ^{6}$. Os economistas descobriram que as agências eram o melhor canal para se comunicar no mercado. Nesta época, há mais ou menos dez anos, eram as agências exclusivas para assinantes, especializadas em notícias econômicas, que davam as cartas. Depois, com a "democratização" da Internet, e a criação do sistema WWW, praticamente todos os jomais do país passaram a ter edições online de seus veículos. Aos poucos, a versão online do jornal descolou-se do modelo de papel para se tornar uma mídia independente com equipes próprias e autônomas.

Este modelo de jornalismo agitou o mercado profissional. Repórteres $\mathrm{e}$ fontes passaram a ter um contato mais assíduo no intuito de alimentar os sites com nolícias em fluxo contínuo. A média de atualização hoje dos sites noticiosos é de quatro minutos.

Os agentes políticos já se deram conta que a guerra política está sendo disputada no espaço da mídia em tempo real. Já ninguém mais espera a edição do "dia seguinte" ou a revista que vai sair no final de semana para tomar conhecimento das últimas notícias. Basta ligar o computador e acessar os sites onde informações quase instantâneas desfilam para o leitor.

Desde a introdução da Internet em 1995, muitos investimentos foram feitos nesta área, principal mente depois que houve a privatização das telecomunicações e as companhias passaram a operar, através de parcerias, na área de produção e distribuição da notícia em rede. As mídias tradicionais transformaram-se e se multiplicaram na Web. Observa-se hoje aqui o fenômeno mundial das fusões e parcerias entre os grandes grupos de produtores de conteúdos e os fornecedores de acesso. Muitos jornais no entanto se enfraquecem neste jogo do mercado e sucumbem à lei do mais forte. Por exemplo, o Jornal do Brasil - JB online, primeiro jornal brasileiro a entrar na Web, afundado em dividas que ultrapassam 300 milhões de dólares. foi vendido recentemente.

No início do ano $2000 \mathrm{um}$ boom de provedores gratuitos invadiu a Web mas, da mesma maneira que chegaram, rápido estão se pulverizando. Isto se explica porque no início as pessoas se cadastram por curiosidade já que é gratuito. Depois param de usá-lo, o que é mortal para quem vive de publicidade. Cai a audiência, desaparece o anunciante.

Diversos pesquisadores chamam a atenção para os riscos da informação gratuita na Internet. Desde 1997, Bernard Miege sugeria a hipótese que a oferta de conteúdos grátis na Internet durante um certo tem- 
po era uma maneira de testar o comportamento dos usuários de modo a desenvolver novas modalidades de valorização e mercantilização da informação. Previsão compartilhada por Gary S. Becker, prêmio Nobel de Economia em 1992 e professor da Universidade de Chicago: A Internet grátis é uma das utopias deste início de século. Antes de dez anos, no máximo, as atividades ligadas à teia serão essencialmente mercantis.

\section{2- A desregulamentação dos papéis: Jornalista ou produtor de conteúdos?}

A constatação de que o jornalismo está mudando impõe aos editores desafios cotidianos que incluem um novo desenho das redações e nova atribuições aos jornalistas.

Para Marc Laimé ${ }^{8}$ a ruptura brutal do exercício da profissão de jornalista pelas novas tecnologias digitais, tende a transformar o jornalista em trabalhador autônomo, privado das garantias contratuais estabelecidas pelas empresas e pelos sindicatos e propenso, fora de qualquer parâmetro ético, a propor seus serviços de " produtor de conteúdos multimídia e multisuporte" a qualquer empresa que exerça uma atividade comercial no setor das comunicações. Financiada por investimentos maciços de diversos fundos de capital de risco que interferem

142 no setor de novas tecnologias da informação, esta ofensiva do novo jornalismo digital pode dar novos contornos à economia das comunicações.

Publicado em outubro de 1998 sob a direção de Alain Accardo, o livro "Journalistes Précaires" analisa em profundidade o processo de precarização que atinge as empresas de comunicação cada vez mais submetidas à lei do mercado, com efeitos desastrosos para os profissionais, que se refletem na qualidade da informação. De fato, os riscos de erros devido à velocidade são grandes. E podem custar o próprio emprego do jornalista.

\section{3- A desregulamentação das funções:}

O amálgama entre jornalistas das empresas e jornalistasfuncionários

A corrida pela informação rápida que deve circular num mínimo de tempo entre o espaço comum, o espaço público e o espaço político (Wolton, 1999) mexe radicalmente com o mercado de trabalho e não fixa o jornalista na empresa. Como não existe diferença entre jornalista e assessor de imprensa no Brasil, entre informação ( jornalismo) e co- 
municação (institucional), mesmo se o exercício simultâneo das duas funções seja dificilmente tolerado pelas empresas, os mesmos jornalistas. sobretudo $\mathrm{em}$ Brasília, podem estar hoje na sucursal de um grande jomal nacional e amanhã colocar-se à serviço do governo.

A adequação dos órgãos de comunicação oficiais dos três poderes (Exccutivo, Legislativo e Judiciário) aos novos tempos da lnternet, criou um espaço de atração para os jornalistas: serviços de alta qualidade profisssional, salários bem acima da média c respeito aos horários de trabalho estabelecidos pelas convenções trabalhistas.

Estima-se nos meios sindicais que cerca de dois mil jornalistas em Brasília tenham escolhido este campo de atividade. Eles trabalham com informação online na comunicação oficial mas se consideram jornalistas como os da mídia tradicional.

Entre as páginas Web mais bem elaborados do DF temos a agência de notícias do Senado Federal e a Agência Brasil (Radiobrás). Através destes portais pode-se aceder a todas as informações relativas aos governo, aos serviços de cidadania e penetrar nos sites da grande imprensal online.

Com cerca de cem jomalistas recrutados por concurso público, a agência do Senado Federal divulga com rapidez e rigor os atos e decisõcs dos senadores. Ela serve também de fonte gratuita para todas as mídias do país, principalmente as do interior que não dispõem de recursos para manter correspondentes na capital. É com orgullho que o diretor da agência online. o jornalista Flavio Mattos. conta que "hoje furamos a Broadcast, com três minutos na frente". Com isso ele quer provar a eficiência da agência oficial diante da concorrencia das mídias privadas onde a competição se mede por frações de segundos.

Outra vantagem para os jornalistas do Poder Legislativo bem como para aqueles que assessoram os Ministérios e demais órgãos públicos federais é a adequação das jomadas de trabalho às convenções estabelecidas. Enquanto que na mídia privada, principalmente nas agências especializadas em notícias online, a jornada de trabalho pode se estender até 12 ou 14 horas, nos poderes públicos o jornalista trabalha no míximo as sete horas previstas por lei para o exercício diário do jornalismo.

Na Radiobrás, uma equipe de jovens recém-formados trabalha em rodízio de cinco horas. Acuin, näo se faz as duas horas extra fixas permitidas para arranjar as empresas. Se somos governo, temos que respeitar a lei," ciiz Cárlos Zarur, que fez da Radiobrás, sob sua direção, um dos portais mais dinâmicos e acreditados do país, com cinco mithões de acesso/mês para notícias online. Até mesmo jornais indepen- 
dentes como a Folha de S.Paulo reproduz entre 20 e 30 notícias da Radiobrás em cada edição. São 300 notícias por dia, sendo que as 30 principais informações são traduzidas em três línguas: espanhol, inglês e alemão.

Ser uma agência especializada em governo e não a favor do governo, esse é nosso objetivo, diz Zarur," explicando que ainda não pode afirmar que a Radiobrás trabalha com TR porque tem um atraso de oito minutos em relação às grandes agências de notícias .

\section{Sites independentes \\ (guias de cidade, cultura, lazer, serviços)}

Entre os sites institucionais e os da imprensa tradicional (mídia impressa e audiovisual online) existe em Brasília uma quantidade incalculável de sites independentes que se dirigem a públicos segmentados. É nesta área que se instalam os "piratas", ou seja, os produtores de Internet não reconhecidos pela legislação em vigor. É contra estes que se insurgem alguns militantes sindicais e certos profissionais que se sentem ameaçados.

Aqui tudo se mistura: serviços, lazer, cultura, concursos e notícias. Alguns chegam mesmo a distribuir notícias em TR sem nenhum jornalista a bordo. Trata-se de um simples "copiar-colar" extraídos dos sites

144 de jornais ou de agências.

\section{www.correioweb.com.br}

Entre os sites especializados em jornalismo, o exemplo do correioweb, versão digital do Correio Braziliense, o maior jornal do DF, merece uma atenção especial.

Privilegiar as notícias locais e servir de guia para diferentes atividades de lazer e entretenimento, além de cidadania, são os principais objetivos do correioweb. Líder em audiência local, a grande maioria dos leitores do correioweb (90\%) moram no DF.

Com uma equipe de 27 pessoas, dos quais apenas sete são jornalistas, o site do CB jorra notícias em fluxo contínuo ao longo do dia, com intervalos médios de um a três minutos. O noticiário é abastecido por agências nacionais e internacionais, por repórteres da redação-papel (pouca colaboração, lamenta Renata Lu, diretora do Correioweb) e pela própria equipe de webjornalistas.

Renata reconhece que é melhor trabalhar com jornalistas formados ou estagiários de jornalismo do que com pessoas de outros 
perfis, embora os jornalistas sejan minoritários na equipe. Ela considera que produzir bons textos ainda é a qualidade fundamental para os jornalistas, em qualquer mídia, inclusive na digital.

Segundo Renata Lu, foi difícil convencer a direção da cmpresal a investir no Correioweb. Hoje o jonal olha o site como um "produto de comunicação". A expressão disso ć a criação de uma unidade de negócio. O serviço online virou uma superintendência. O grupo recebeu noção de mercaldo, produto e negócio. Entre janeiro e junho de 2000 foi lançado o novo site com equipe ampliada e com característica multidisciplinares: web designers, produtores de Internet, jornalistas, publicitários, vendas.

Atualmente o Correioweb tem cerca de oito milhões de acessol mês. Mas não conseguiu equilibrar suas contas internas. A publicidade não chega a financiar o site que é mantido por outras mídias da casa.

\section{4- A desregulamentação das rotinas produtivas: jornadas infernais de 12 horas ou mais}

Seguindo uma tendência mundial, as redações dos jomais online são separadas do jornal papel. E não existe praticamente nenhuma ligação entre elas. As rotinas produtivas do jornalismo online são semelhantes no que se refere à coleta de informações. O que muda fundamentalmente é a distribuição das notícias. Porque a palavra de ordem é TR, todos os jornalistas estão conectados permanentemente a seus celulares. Entre o momento em que o fato acontece e sua divulgação em rede, a média é quatro a cinco minutos para os jornais online e "zero segundo" para as agências em TR, tipo Broadcast (Estado de $S$. Paulo) e Investnews (Gazeta Mercantil), que trabalham com tecnologias de satélite próprias e clientes assinantes.

Os jornalistas trabalham com múltiplos horários de fechamento. A notícia é constantemente renovada, no mesmo ritmo das agências. A informação cresce palavra por palavra, linha por linha, na medida em que os acontecimentos se produzem. Evidentemente que este ritmo se aplica para os grandes fatos sociais, políticos e econômicos que podem colocar em risco a estabilidade das instituições. Mas o que prevalece no TR são as notícias econômicas de interesse do mercado financeiro.

A diferença essencial entre jornalistas da mídia tradicional e da mídia digital reside no ritmo das rotinas produtivas. Rotinas infernais, como descreve F.M.,26 anos, jornalista do "Valor Econômico". Como seus colegas, ela trabalha 12 horas por dia, de 9 às 21 horas. As jornadas 
plenas são recompensadas com altos salários e uma imagem profissional consolidada antes dos 30 anos. O Sindicato não dispõe de dados sobre a idade média dos webjornalistas, mas estima-se que a maioria seja formada por pessoas com menos de 30 anos.

\section{A desregulamentação do estatuto profissional (sindicato, empresas, faculdades)}

O exercício profissional do jornalismo no Brasil constitui uma reserva de mercado regulamentada por uma série de decretos e leis. Mas nos últimos anos vem se acentuando a pressão de algumas grandes empresas no sentido de abrir mão destas exigências para o recrutamento de profissionais. Há discussões no sentido de dispensar a exigência do diploma fornecido pelas faculdades de Comunicação para o exercício da profissão. Os sindicatos, de um modo geral, não estão dispostos a renunciar ao diploma mas eles propõem que a concessão e o controle dos registros profissionais de jornalistas seja da competência da Federação Nacional de Jornalistas (FENAJ), órgão que reagrupa todos os sindicatos do país, e não mais do Ministério do Trabalho, como exige a legislação.

O jornal da Fenaj chama a atenção para a necessidade de desenvolver ações com o objetivo de que sejam oferecidas condições mínimas

146 da CLT (jornada de trabalho de cinco horas) e das convenções e acordos coletivos de trabalho (pisos e outras vantagens), para os profissionais que trabalham em jornalismo online, conforme as discussões dos jornalistas reunidos em seu XXIX Congresso, em Salvador, em setembro de 2000 .

"Neste sentido é preciso que os sindicatos da categoria de todo o país abram negociações com jornais e provedores de Internet com a finalidade de estender aos jornalistas desta nova mídia os benefícios existentes nas convenções de trabalho assinadas com a entidade patronal que reúne as empresas de jornais e revistas", diz o artigo.

A categoria defende explicitamente a necessidade de garantir esse espaço como privativo do jornalista. A Fenaj também manifesta a intenção de realizar estudo jurídico sobre o trabalho jornalístico na Internet com o objetivo de reunir subsídios para combater o exercício irregular da profissão.

Enquanto isso as universidade públicas e privadas continuam jogando milhares de jornalistas no mercado. Segundo dados da Fenaj, estima-se que as 120 faculdades e cursos de Comunicação ${ }^{10}$ existentes no país formem, por ano, cerca de oito mil jornalistas.

Desde 1938, quando tornou-se obrigatório o registro profissional no 
Ministério do Trabalho, foram emitidos cerca de 90 mil registros no país. Em 1997, uma pesquisa da Fenaj revelou que aproximadamente 20 mil jornalistas estavam em atuação nas empresas privadas com carteira assinada. Este cálculo não inclui free-lances, pessoas jurídicas, servidores públicos e pessoas que sejam contratadas com denominações diferentes das relacionadas pelos decretos.

Por exemplo, o termo produtor de conteúdos não ć contabilizado, explica Francisco Sant'Anna, vice-presidente da Federação Internacional de Jornalista (FIJ) e ex-presidente do Sindicato de Jomalistas de Brasília".

Até março de 2001 a Delegacia Regional de Trabalho do Distrito Federal havia emitido 4.700 registros profissionais de jornalistas. Uma pesquisa realizada pelo Sindicato de Jornalistas em 1992, apontou a existência de cerca de dois mil jornalistas que migraram de outros Estados para Brasília, já com o registro profissional, atraídos pelas promessas de altos salários, proximidade com o poder, boa qualidade de vida, possibilidades de fazer extras com consultorias em comunicação para órgãos governamentais ou ONGs. Somados estes números, temos em Brasília 6700 jornalistas.

Mas Sant'Anna esclarece também que estes números podem não ser exatos, pois não são atualizados com regularidade. Ele admite que deste total não se poderia afirmar que todos estão em exercício. Quanto à distribuição dos profisssionais no mercado do DF, ele estima que cerca de 1500 jornalistas estão na grande imprensa, outros dois mil nos órgãos públicos e institucionais e os demais vivem de free-lances, assessorias de imprensa, sites de informação independentes, estão desempregados, mudaram de profissão ou morreram.

\section{Conclusão}

As transformações provocadas pelas novas tecnologias da comunicação na produção, edição e distribuição da informação online ainda estão acontecendo. Estamos em processo de transição. Seria precipitado tirar conclusões no decorrer do processo. Mas já sabemos que a Internet, como nova mídia, já modificou profundamente o modo de fazer jornalismo no Brasil e no mundo. Os conceitos tradicionais de jornalismo estão em discussão levando-se em conta novos paradigmas.

Estudos revelam também que o internauta brasileiro tem algo de peculiar : ao acessar a Internet, ele busca, em primeiro lugar, a informação. Ele quer se atualizar, estar em dia com o mundo contemporâneo.

Um estudo desenvolvido pelo American Journalism Review News desde 1994 aponta que os Estados Unidos lideram o número de publi- 
cações online. Dos 4.925 sites de notícias registradas pelo ARJ até setembro de 1998, 3.622 pertencem a empresas de comunicação americana. Segundo dados do Media Metrix, entre outubro 1998 e abril 2000, a média de acesso de usuários aos sites foi de dez mil naquele
país.

Mas a audiência dos jornais online brasileiros é maior que a dos jornais americanos. Segundo dados do Ibope, pesquisa realizada em 1999, 50\% dos 25 mil internautas entrevistados afirmaram que navegam na Internet em busca de informações. O site do jornal $O$ Estado de S. Paulo recebe 68 mil visitas diárias. O Último Segundo, site de notícias em tempo real, tinha em julho uma audiência média de 402.989 acessos/dia contra 145.108 acessos/dia em maio. ${ }^{12}$

Em meio à crise internacional que atinge a imprensa, o Brasil é um dos países onde os jornais vêm apresentando índices de crescimento há três anos. As tiragens aumentaram em 69,43\% desde 1990. A média de circulação diária passou de 6,892 no início de 1998 para 7,245 em 1999. Este crescimento foi mantido em 2000 . O mercado publicitário vem acompanhando este crescimento. Os investimentos aumentaram em $1,6 \%$ entre 1998 e $2000 .^{13}$

As grandes linhas das empresas brasileiras de comunicação são definidas em função da interface das novas mídias diante das quais os jornais adotaram mudanças estratégicas.

148 Entre 1998 e 2000 a grande mídia investiu no desenvolvimento de suas relações com a Internet. Em 1999, 192 jornais já tinham versões digitais. A grande imprensa tenta fazer da Internet uma aliada e não uma concorrente. Investindo na Internet, as empresas conseguiram aumentar suas tiragens e o número de seus leitores. Milhões de dólares foram investidos no ano passado em parcerias com outros negócios.

A Folha de S. Paulo deu o maior salto neste sentido. Em 1995 ela criou seu próprio provedor, o Universo online - UOL, líder do mercado brasileiro. Atualmente, $25 \%$ do faturamento do grupo vem do UOL, que vale mais do que o próprio jornal: entre 2,5 e 3 milhões de dólares, segundo o diretor financeiro da UOL, Elemer Surany.

Apesar disso, a UOL não gera lucros e opera "no vermelho" diante da concorrência da American Online (AOL) e dos espanhóis do Terral Telefonica. As perdas são cobertas pelos acionistas que esperam obter lucros em 2002 com a venda de ações para a Embratel.

Falamos de transações comerciais para explicar a estratégia da Folha, que acredita no desenvolvimento do jornalismo online.

Entramos na Internet porque tínhamos certeza de que quem estivesse fora ficaria para trás. Mas agora já é dificil diferenciar o futuro do jornal do UOL, diz Octavio Frias de Oliveira, diretor do grupo. 
Segundo Frias, a Internet prepara as empresas para um cenário de perda de importância das áreas tradicionais. Neste quadro, o conteúdo passará a ter cada vez mais importância no faturamento das empresas.

No futuro a redação deverá crescer. Haverá o fortalecimento do jornalismo da empresa e do profissional de imprensa, prevê Octavio Frias de Oliveira. ${ }^{14}$

Isto demonstra que a informação é um produto de valor em alta. Mas, e o jornalista? Terá ainda valor como produtor de sentidos na medida em que o conceito de informação como direito e como bem público se trar sforma em mercadoria veloz, estratégica e perecível na sociedade da informação?

\section{Notas}

\section{Dados do Código Brasileiro de Ocupação Profissional ( $C B O P$ )}

2 BRANDÃO, Elizabeth Pazito - Da Ciência ao mercado, a informação em tempo real - tese de Doutorado- UnB - dezembro 1999

3 MULLER, Carlos Alves. A Galáxia de Gutenberg rumo ao cyberespaço. As experiências dos jornais com as novas tecnologias de comunicação. Paper apresentado ao GT de Politicas Nacionais de Comunicação - INTERCOM 95)

4 "real time", em inglês - Em informática o termo sigifica a operação de um computador que realiza determinada operação vinculada ao tempo cronológico de sua execução

5 on line - em informática é a palavra que designa a operação de um equipamento periférico em comunicação direta com a unidade central de processamento de um computador diretamente de seu ponto de origem, sem sofrer alterações ou tratamento intermediário

6 Paiva, Jacqueline- Monografia sobre noticiário econômico em TR Pós-graduação em Com;/FAC/UnB

7 A antecipação de uma conversa entre o presidente do Senado, Antonio Carlos Magalhães e três procuradores da República na edição online da revista Isto É (28/02/01) precipitou a queda de dois ministros do governo.

8 LAIME, Marc- Les nouveaux barbares de l'information em ligne Le Monde Diplomatique - juillet 1999

9 Todas as informações sobre os sites governamentais foram obtidos em depoimento à autora 
10 Estamos nos referindo a instituições públicas e privadas que já estão há mais tempo formando jornalistas. Não contabilizamos as mais recentes que ainda não têm tempo hábil para diplomar jornalistas.

11 em depoimento à autora

12 Dados de MOHERDAUI Luciana - Guia de Estilo Web - produção e distribuição de notícias online - São, Paulo-Senac- 2000

13 Momento de Definições - Relatório de atividades da ANJ - Assóciação Nacional de Jornais- 1998-2000

14 As informações relativas à Folha de S. Paulo e a UOL, bem como as declarações em itálico, foram extraídas do suplemento especial relativo aos 80 anos do jornal publicado em fevereiro de 2001.

\section{Bibliografia}

AUBENAS, Florence e BENASAYAG, Miguel - La Fabrication de l'Information, Paris, La Découverte, 1999

150 LAIMÉ, Marc-Les Nouveaux Barbares de l'Information en ligne - Le Monde Diplomatique, juillet 1999

LEVACOV, Marília e outros - Tendências na Comunicação - Porto Alegre, L\&PM, 1998

MANTA, André - Jornalismo na Era Digital - Um Panorama dos Jornais na Internet - Monografia de conclusão do curso de Comunicação Social da Universidade Federal da Bahia, Salvador, 1996 http://www.facom.ufba.br./pesq/cyber/manta/index.html.

MARCONDES FILHO, Ciro - Comunicação e Jornalismo - A Saga dos Cães Perdidos, São Paulo, Hacker editores, 2000

MEDINA, Cremilda - Profissão jornalista, responsabilidade social Rio de Janeiro, Forense, 1982

MOHERDAUI, Luciana - Guia de Estilo Web - Produção e edição de notícias online- Sâo Paulo- Senac ,2000

RIBEIRO, Jorge Cláudio - Sempre Alerta - cóndições e contradições do trabalho jornalístico - São Páulo, Brasiliense, 1998 .

RUELLAN , Denis - Une médiation pour une médiatisation Hermès ( CNRS) $n^{\circ} 21,1997$ 
Denis - Groupe professionnel e marché de travail du journalisme - Réseaux, nº 81. janvier 1997

Denis - Les "pro"du journalisme. De l'état au statut, la construction d'un espace professionnel"- Rennes, PUR, col Res Publica, 1997, 170 páginas

Denis, THIERRY Daniel - Productions en réseaux et mutations professionnelles du joumalisme - Programme de recherche de l'Observatoire des NTIC et des métiers dans le cadre du Plan Régional ITR - Bretagne - Département Information/Communication IUT de Lannion, 1977

Denis - Contrer les évidences de l'identité journalistique Polis ( GRAPS- Cameroun - nº 5, 1988

Denis, PALMER Michael, LACAN Jean-François - Les Joumalistes, Paris, Syros, 1994

THIERRY, Daniel (org): Nouvelles Technologias de Communication Paris, Harmattan , 2000

TRAQUINA,Nelson (org) - Jornalismo: questōes, teorias e estórias Lisboa, Comunicação e Linguagem - Veja- 1993

WOLTON,Dominique - Internet et après? - Paris, Flammarion, 1999 Dominique - Penser la Communication - Paris, Flammarion, 1997

E diversos artigos da mídia em geral através do acompanhamento diário das novidades no mundo digital.

Tivemos também informaçōes de fontes diretas do mercado de trabalho no DF. As declarações foram obtidas em entrevista com a autora.

\section{Palavras-chaves:}

1. jornalismo online

2. regulamentação profissional

3. novas tecnologias

4. Internet

5. produção de conteúdos 


\section{DOSSIÊ}

O cinema de Quentin Tarantino e suas três principais formas de apresentação

Nas entranhas da América: breve análise sobre o cinema de David Lynch

Imagens do Brasil pelas lentes estrangeiras (sob a luz do cinema de ficção)

\section{ARTIGOS}

Memória e Identidade Social

Hackers no Brasil

Do Napster e Gnutella ao Projeto Freenet

Samba, futebol e democracia? A cobertura do movimento "Diretas Já" pela imprensa francesa

Do oral ao hipertextual: a biografia na produção cultural contemporânea

Informação on-line: jornalista ou produtor de conteúdos? contracampo 